\title{
Observation of Bimodal LLDPE/TiO Nanocomposites Produced by in situ Polymerization with Zirconocene/MMAO Catalysts via Ga Modification on $\mathrm{TiO}_{2}$ Nanofiller
}

\author{
Ekrachan Chaichana $^{1}$, Somsakun Pathomsap ${ }^{2}$, Takeshi Shiono ${ }^{3}$, and Bunjerd Jongsomjit ${ }^{2, *}$ \\ 1 Chemistry Program, Faculty of Science and Technology, Nakhon Pathom Rajabhat University, Nakhon \\ Pathom 73000, Thailand \\ 2 Center of Excellence on Catalysis and Catalytic Reaction Engineering, Department of Chemical \\ Engineering, Faculty of Engineering, Chulalongkorn University, Bangkok 10330, Thailand \\ 3 Department of Applied Chemistry, Graduate School of Engineering, Hiroshima University, Higashi- \\ Hiroshima 739-8527, Japan \\ *E-mail: bunjerd.j@chula.ac.th (Corresponding author)
}

\begin{abstract}
Nano- $\mathrm{TiO}_{2}$ and its modification with gallium (nano- $\mathrm{TiO}_{2}-\mathrm{Ga}$ ) and zirconium (nano$\mathrm{TiO}_{2}-\mathrm{Zr}$ ) were used here as nanofillers in production of linear low-density polyethylene (LLDPE). The nanoparticles were immobilized by modified-methyl aluminoxane (MMAO) to be a catalytic filler prior to introducing into the in situ polymerization of ethylene and 1-hexene using zirconocene catalyst, and consequently produced $\mathrm{LLDPE} / \mathrm{TiO}_{2}$ nanocomposites. It was found that the modified nano- $\mathrm{TiO}_{2}$ by $\mathrm{Ga}$ and $\mathrm{Zr}$ can hold more amount of MMAO on the surface than the unmodified one. This is because the modified particles have a stronger interaction between MMAO and the surface, as observed by thermal gravimetric analysis (TGA). However, the stronger interaction leads to lower catalytic activities for the polymerization systems. Observing from the molecular weight distribution (MWD) of the resulting products, it was found that the modified nano- $\mathrm{TiO}_{2}$ with $\mathrm{Ga}$ can produce the $\mathrm{LLDPE} / \mathrm{TiO}_{2}$ nanocomposites with bimodal MWD. This result was due to the heterogeneity of the surface after modification, which can generate the multiple active sites for the catalyst, leading to multimodal properties of the polymer.
\end{abstract}

Keywords: Polymer nanocomposite, metallocene, nano- $\mathrm{TiO}_{2}$, XPS.

ENGINEERING JOURNAL Volume 17 Issue 3

Received 6 November 2012

Accepted 11 March 2013

Published 1 July 2013

Online at http://www.engj.org/

DOI:10.4186/ej.2013.17.3.33 


\section{Introduction}

Polymer composites are the polymer in which a filler such as fibre, whiskers and particles are embedded. They are created in order to overcome some drawback properties of the host polymers with the distinguished properties of the fillers. In general, polymer composites can be prepared by three methods: (i) a melt mixing [1-3], (ii) a solution blending [4] and (iii) in situ polymerization [5-7]. Due to the direct synthesis via polymerization along with the presence of fillers, the in situ polymerization is perhaps considered to be the most promising technique to produce polymer composites with homogeneous distribution of the particles inside the polymer matrix.

For the in situ polymerization, it is because the fillers were introduced during polymerization, the mechanism of polymer growth can be influenced by the properties of introduced fillers. This differs from the other methods, which the fillers are introduced after the polymers are completely formed. Therefore, the fillers in those methods cannot affect the growth mechanism of the polymers. The polymer growth mechanism controls many polymer properties including molecular weight (MW) and molecular weight distribution (MWD). For example, the growth mechanism with the fast chain transfer reaction can provide the polymer product with the low MW [5], and on the other hand, the high MW can be obtained with the slow chain transfer reaction. Polymers, which consist of two fractions of different molecular weights (low and high MW) are classified as bimodal polymers or bimodal MWD polymers due to having two molecular weight distribution maxima. Bimodal MWD polymers have good mechanical and rheological properties beneficial from the fractions of high MW and low MW. As mentioned above, the different MW fractions of polymers can be obtained by varying the growth mechanism. Hence, if the fillers introduced into the polymerization system have the ability to create various growth mechanisms to the system, they may produce polymers consisting of two different MW fractions or bimodal MWD polymers.

In general, a mixture of two catalysts has usually been used to produce a bimodal MWD polymer due to naturally posing dual active sites [6-7]. However, by a heterogeneous catalytic system, only one catalyst fixed on the certain support (filler) can generate dual active sites due to the heterogeneity of the support. As observed by our previous work [8] using micro- $\mathrm{TiO}_{2}$ as a support for zirconocene/MAO catalyst, it also found that this catalytic support can produce a bimodal MWD polymer. For further study in production of bimodal MWD polymer here, the $\mathrm{TiO}_{2}$ in nanometer scale (nano- $\mathrm{TiO}_{2}$ ) was used instead for gaining an advantage of nanotechnology to the resulting product, along with its modification by gallium (Ga) and zirconium $(\mathrm{Zr})$, which have been proven previously as a good modifier in the catalytic system $[9,10]$. Those modifiers were aimed to enhance some properties of the nano- $\mathrm{TiO}_{2}$, and also the polymer nanocomposites product particularly in generating bimodal properties. In addition, to get better understanding in the role of the fillers taking in the in situ polymerization, a variety of parameters changed in the polymer composites resulted from the fillers need to be concerned. Thus, in this study, the efficient techniques i.e. X-ray diffraction (XRD), X-ray photoelectron spectroscopy (XPS), ${ }^{13}$ carbon nuclear magnetic resonance ${ }^{13} \mathrm{C}$ NMR) and gel permeation chromatography (GPC) were used here for measuring the changed parameters in the fillers and the polymer nanocomposite products.

\section{Experimental}

\subsection{Materials}

All the chemicals and the polymerization were perfomed under an argon atmosphere using a glove box and/or Schlenk techniques. Titanium (IV) oxide nanopowder (100\% anatase, $\left.\mathrm{TiO}_{2}\right)$, Gallium (III) nitrate hydrate (99.9\%) and Zirconium (IV) n-propoxide $70 \mathrm{wt} \%$ solution in 1-propano were purchased from the Aldrich Chemical Company. Toluene was dried over dehydrated $\mathrm{CaCl}_{2}$ and distilled over sodium/benzophenone before use. The rac-ethylenebis (indenyl) zirconium dichloride ( $\mathrm{rac}-\mathrm{Et}[\mathrm{Ind}] \mathrm{ZrCl}_{2}$ ) was obtained from the Aldrich Chemical Company, Inc. Modified methylaluminoxane (MMAO) in hexane was donated by Tosoh (Akzo, Japan). Trimethylaluminum (TMA, $2 \mathrm{M}$ in toluene) was supplied by Nippon Aluminum Alkyls, Ltd., Japan. Ultrahigh purity argon was purchased from Thai Industrial Gas Co., Ltd., and further purified by passing it through columns that were packed with BASF catalyst R3-11G (molecular-sieved to $3 \AA$ ), sodium hydroxide $(\mathrm{NaOH})$, and phosphorus pentaoxide $\left(\mathrm{P}_{2} \mathrm{O}_{5}\right)$ to remove traces of oxygen and moisture. Ethylene gas $(99.96 \%)$ was donated by the National Petrochemical Co., Ltd., Thailand. 1-Hexene $(99 \%, \mathrm{~d}=0.673 \mathrm{~g} / \mathrm{mL})$ was purchased from Aldrich Chemical Company, Inc. 


\subsection{Modification of $\mathrm{Nano}^{-\mathrm{TiO}_{2}} \mathrm{Nanoparticles}$}

Ga-modified $\mathrm{TiO}_{2} / \mathrm{Zr}$-modified $\mathrm{TiO}_{2}$ fillers were prepared by incipient wetness impregnation method. A designed amount of gallium (III) nitrate hydrate / zirconium (IV) n-propoxide was dissolved in deionized water, and then impregnated into the nano- $\mathrm{TiO}_{2}$ fillers with $1 \mathrm{wt} \% \mathrm{Ga}$ and $1 \mathrm{wt} \% \mathrm{Zr}$ by calculating of the required amounts of $\mathrm{Ga} / \mathrm{Zr}$ loading. The fillers were dried at $110^{\circ} \mathrm{C}$ for 12 hours and calcined in air at $500^{\circ} \mathrm{C}$ for 4 hours for $\mathrm{Ga}$ modification and calcined at $350^{\circ} \mathrm{C}$ for 2 hours for $\mathrm{Zr}$ modification.

\subsection{In Situ Polymerization Reaction}

The ethylene and 1-hexene copolymerization reaction was carried out in a $100 \mathrm{ml}$ semi-batch stainless steel autoclave reactor equipped with a magnetic stirrer. Using a glove box, the desired amount of the nano- $\mathrm{TiO}_{2}$ was placed into the reactor and magnetically stirred with $1.14 \mathrm{ml}$ of MMAO for $30 \mathrm{~min}$. Then, toluene was introduced into the reactor to a total volume of $30 \mathrm{ml}$. Separately, the desired amount of Et(Ind) $\mathrm{ZrCl}_{2}(5 \times$ $\left.10^{-5} \mathrm{M}\right)$ and TMA $\left([\mathrm{Al}]_{\mathrm{TMA}} /[\mathrm{Zr}]_{\mathrm{cat}}=2500\right)$ was mixed and stirred for a 5 -min aging process at room temperature. This mixture was then injected into the reactor. The reactor was frozen in liquid nitrogen to stop the reaction, and then injected $0.018 \mathrm{~mol}$ of 1 -hexene. The reactor was evacuated to remove the argon atmosphere, and was then heated up to the polymerization temperature $\left(70^{\circ} \mathrm{C}\right)$. To start the polymerization, 0.018 mole of ethylene (at 6 psi gauge) was fed into the reactor containing the 1-hexene and catalyst mixtures. After the ethylene was totally consumed, the reaction was terminated by the addition of acidic methanol and then stirred for $30 \mathrm{~min}$. The copolymer product (white powder) was filtered, washed with methanol and dried at room temperature.

\subsection{Characterization of $\mathrm{Nano}^{-\mathrm{TiO}_{2}}$ Nanoparticles}

1) X-ray diffraction $(\mathrm{XRD})$ : $\mathrm{XRD}$ was performed to determine the bulk crystalline phases of the samples using a Siemens D-5000 X-ray diffractometer with $\mathrm{Cu} \mathrm{K}_{\alpha}(\mathrm{k}=1.54439 \AA)$. The spectra were scanned at a rate of $2.4^{\circ} / \mathrm{min}$ in the range $2 \theta=20-80^{\circ}$.

2) BET surface area: Surface area measurement was carried out by low temperature nitrogen adsorption in a Micromeritic ChemiSorb 2750 system.

3) Scanning electron microscopy (SEM): SEM was used to investigate the sample morphology of the nano- $\mathrm{TiO}_{2}$. A JEOL mode JSM-5800 LV scanning microscope was employed.

4) Transmission electron microscopy (TEM): TEM was used to determine the shape and crystalline size of the nano- $\mathrm{TiO}_{2}$. Samples were dispersed in ethanol prior to TEM measurement a JEOL JEM-2010).

\subsection{Characterization of MMAO-Supported Fillers}

The fillers were prepared in the similar condition of using for in situ polymerization except that they were dried to remove the solvent prior to characterization.

1) Thermal gravimetric analysis (TGA): TGA was performed using a TA Instruments SDT Q-600 analyzer. Samples of $10-20 \mathrm{mg}$ were examined at a temperature ramping from 25 to $600^{\circ} \mathrm{C}$ at $2^{\circ} \mathrm{C} / \mathrm{min}$. The carrier gas was $\mathrm{N}_{2} \mathrm{UHP}$.

2) X-ray photoelectron spectroscopy (XPS): XPS was used to determine the binding energy (BE) and the amount of $\mathrm{Al}$ on sample surfaces. It was carried out using the Shimazu AMICUS with VISION 2control software. Spectra were recorded at room temperature in high-resolution mode $(0.1 \mathrm{eV}$ step, $23.5 \mathrm{eV}$ pass energy) for $\mathrm{Al} 2 \mathrm{p}$ core-level region. The samples were mounted on pieces of adhesive carbon tape as pellets. The energy reference for $\mathrm{Ag}$ metal $(368.0 \mathrm{eV}$ for $3 \mathrm{~d} 5 / 2)$ was used for this study.

\subsection{Characterization of Polymer}

1) Differential scanning calorimetry (DSC): DSC was used to determine the melting temperature of ethylene/1hexene copolymer products with a Perkin-Elmer Diamond DSC. The analyses were performed at a heating rate of $20^{\circ} \mathrm{C} / \mathrm{min}$ in the temperature range of $50-150{ }^{\circ} \mathrm{C}$.

2) ${ }^{13}$ Carbon nuclear magnetic resonance $\left({ }^{13} \mathrm{C} N M R\right):{ }^{13} \mathrm{C}$ NMR spectroscopy was used to determine 1-hexene incorporation and copolymer microstructure. Each sample solution was prepared by dissolving $50 \mathrm{mg}$ 
of copolymer in 1,2-dichlorobenzene and $\mathrm{CDCl}_{3}$. The ${ }^{13} \mathrm{C}$ NMR spectra were taken at $100{ }^{\circ} \mathrm{C}$ using a Bruker Advanced II 400 operating at $100 \mathrm{MHz}$ with an acquisition time of $1.5 \mathrm{~s}$ and a delay time of $4 \mathrm{~s}$.

3) Gel permeation chromatography: The molecular weight of polymer was determined using gel permeation chromatography (GPC, PL-GPC-220). Samples were prepared having approximately concentration of $1-2 \mathrm{mg} / \mathrm{ml}$ in trichlorobenzene (mobile phase) by using the sample preparation unit (PL-SP 260) with filtration system at a temperature of $140{ }^{\circ} \mathrm{C}$. The dissolved and filtered samples were transferred into the GPC instrument at $140{ }^{\circ} \mathrm{C}$. The calibration was conducted using the universal calibration curve based on narrow polystyrene standards.

\section{Results and Discussion}

\subsection{Characteristics of Nanoparticles}

Nano- $\mathrm{TiO}_{2}$ particles (designated by $\mathrm{TiO}_{2}$ ) was employed here as a filler along with the two modifications of them by $\mathrm{Zr}\left(\mathrm{TiO}_{2}-\mathrm{Zr}\right)$ and $\mathrm{Ga}\left(\mathrm{TiO}_{2}-\mathrm{Ga}\right)$. BET surface areas of the fillers were in order of; $\mathrm{TiO}_{2}-\mathrm{Ga}>$ $\mathrm{TiO}_{2}-\mathrm{Zr}>\mathrm{TiO}_{2}\left(120,99\right.$, and $88 \mathrm{~m}^{2} / \mathrm{g}$, respectively). It can be seen that both modifiers increased surface area of the nano- $\mathrm{TiO}_{2}$, and seemed not to block the pores of the main particles. The XRD patterns of the fillers shown in Fig. 1 were similar having XRD peaks at $25^{\circ}, 37^{\circ}, 48^{\circ}, 55^{\circ}, 56^{\circ}, 62^{\circ}, 69^{\circ}, 71^{\circ}$, and $75^{\circ}$ assigning to presence of anatase $\mathrm{TiO}_{2}$. No characteristic peaks of $\mathrm{Zr}$ or Ga were observed. This indicated that $\mathrm{Zr}$ and $\mathrm{Ga}$ were present in the highly dispersed form in nano- $\mathrm{TiO}_{2}$ fillers, then being invisible by XRD. In addition, useful techniques i.e. SEM and TEM (Figs. 2 and 3) were used to examine the entire fillers to obtain the more details of them including morphology and particle size, but nevertheless no difference in those details was observed among them.

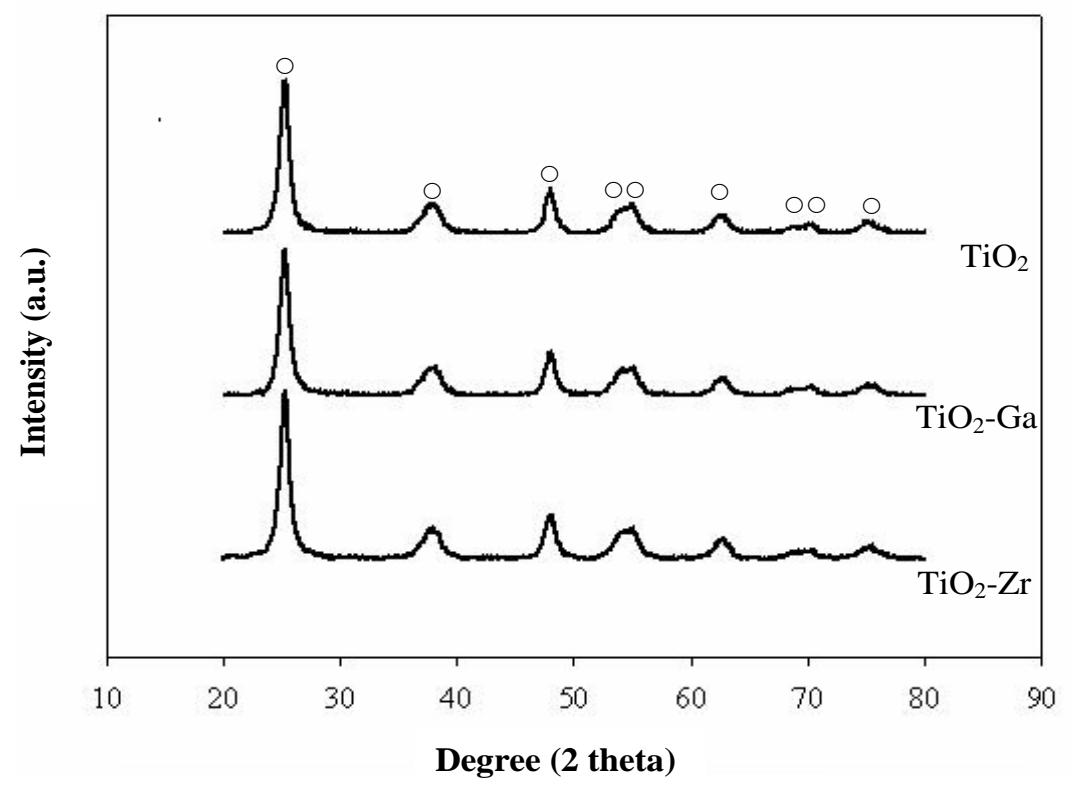

Fig. 1. XRD patterns of nano- $-\mathrm{TiO}_{2}$ fillers with different modifications; where (o) refers to anatase characteristic peak. 

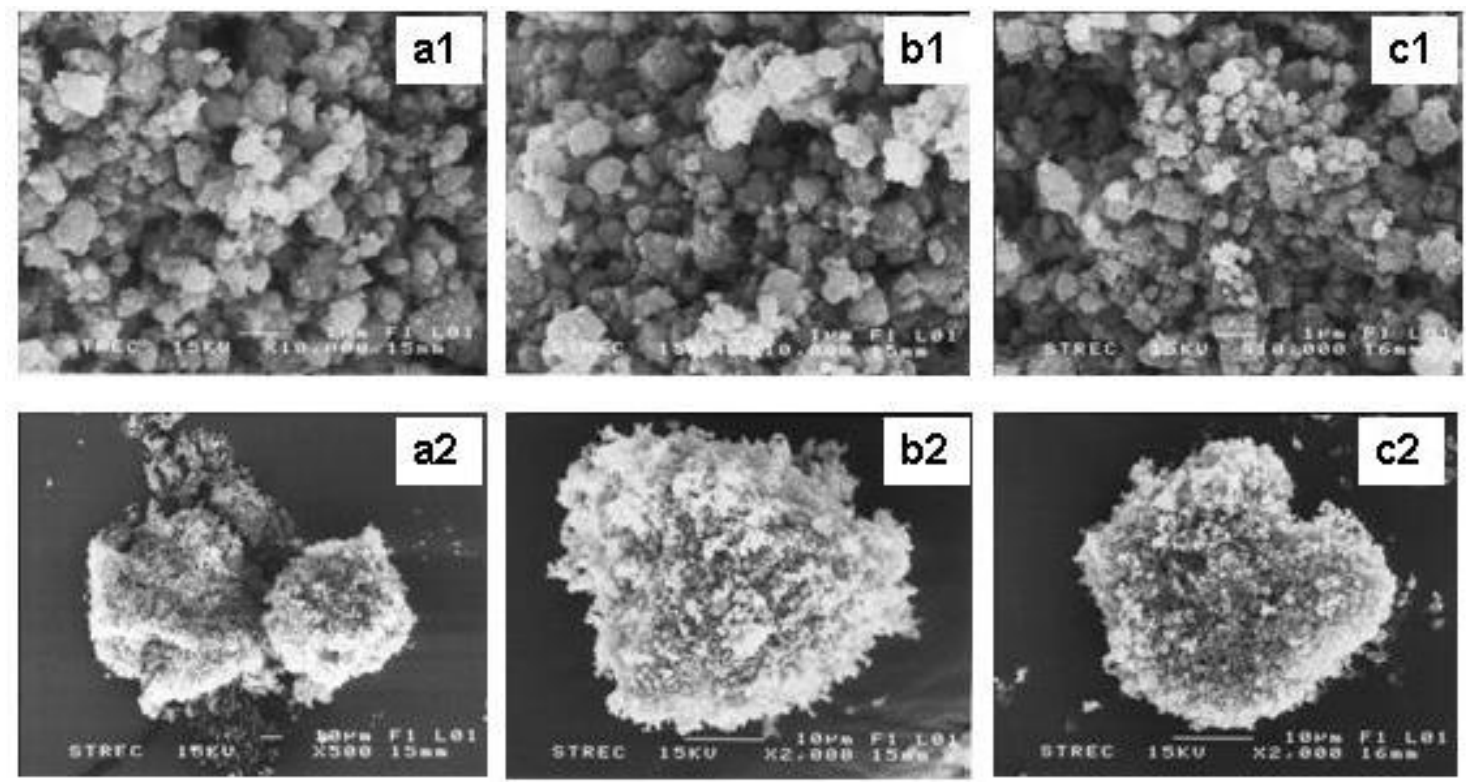

Fig. 2. SEM images of nano-TiO fillers; (a1)/(a2): $\mathrm{TiO}_{2}$; (b1)/(b2): $\mathrm{TiO}_{2}-\mathrm{Ga}$; and (c1)/(c2): $\mathrm{TiO}_{2}-\mathrm{Zr}$.

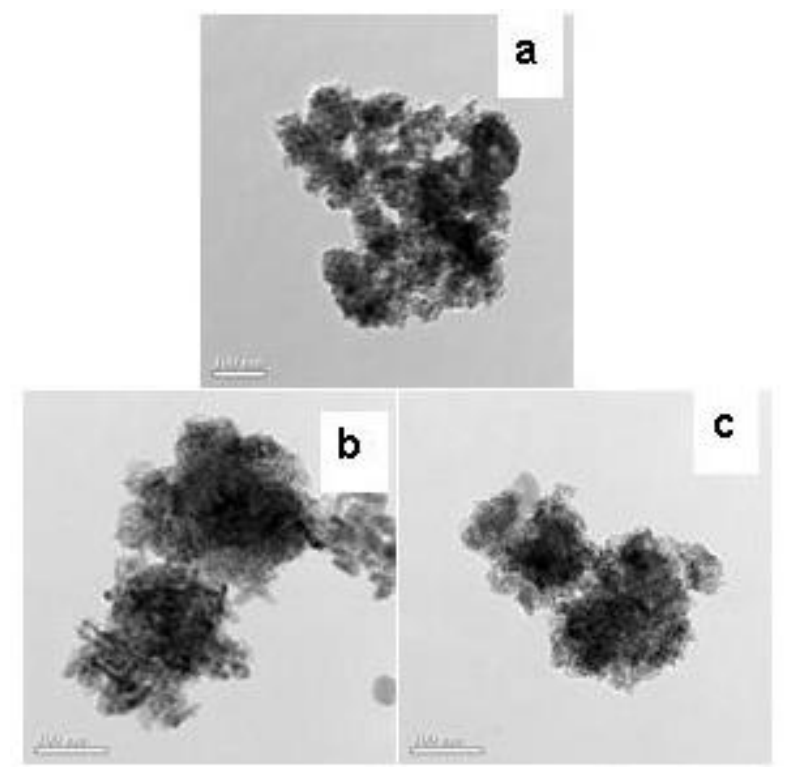

Fig. 3. TEM images of nano- $\mathrm{TiO}_{2}$ fillers; (a) $\mathrm{TiO}_{2}$; (b) $\mathrm{TiO}_{2}-\mathrm{Ga}$; and (c) $\mathrm{TiO}_{2}-\mathrm{Zr}$.

TGA measurement is one of the powerful techniques that can provide basic properties of the filler needed for used in in situ polymerization. The degree of interaction of the fillers and the MMAO cocatalyst, which engaged on them through the $\mathrm{O}_{\text {filler--- }} \mathrm{Al}_{\text {MMAO }}$ linkage [11] was also investigated by the TGA measurement. MMAO plays a crucial role in the catalytic system, such as being an activating agent and also a stabilizer for a cationic metallocene alkyl and/or counter-ion, and so on [9]. As a result, the interaction between MMAO and the fillers affected directly to the performance of MMAO, and consequently the catalytic activity of the system. As a matter of fact, too strong interaction can result in it being more difficult for the MMAO engaged with the fillers to react with metallocene catalyst during activation processes, leading to low activity for polymerization. Therefore, the entire fillers immobilized with MMAO were measured by TGA measurement in order to prove the interaction between them and MMAO.

The TGA can provide the degree of interaction in terms of weight loss and removal temperature as seen in Fig. 4. It was found that the weight loss of MMAO on each filler was in the order of $\mathrm{TiO}_{2}-\mathrm{Ga}$ $(16.3 \%)<\mathrm{TiO}_{2}-\mathrm{Zr}(16.8 \%)<\mathrm{TiO}_{2}(18.3 \%)$. This indicated that the $\mathrm{MMAO}$ present on the $\mathrm{TiO}_{2}-\mathrm{Ga}$ filler 
exhibited the strongest interaction, followed by $\mathrm{TiO}_{2}-\mathrm{Zr}$ and $\mathrm{TiO}_{2}$, respectively. The TGA results also suggest that the modification by $\mathrm{Ga}$ and $\mathrm{Zr}$ caused alteration in interaction of the main fillers $\left(\mathrm{TiO}_{2}\right)$. These results agree with the finding of our previous works $[10,15,16]$, which exhibited the similar results even differed in type of the fillers.

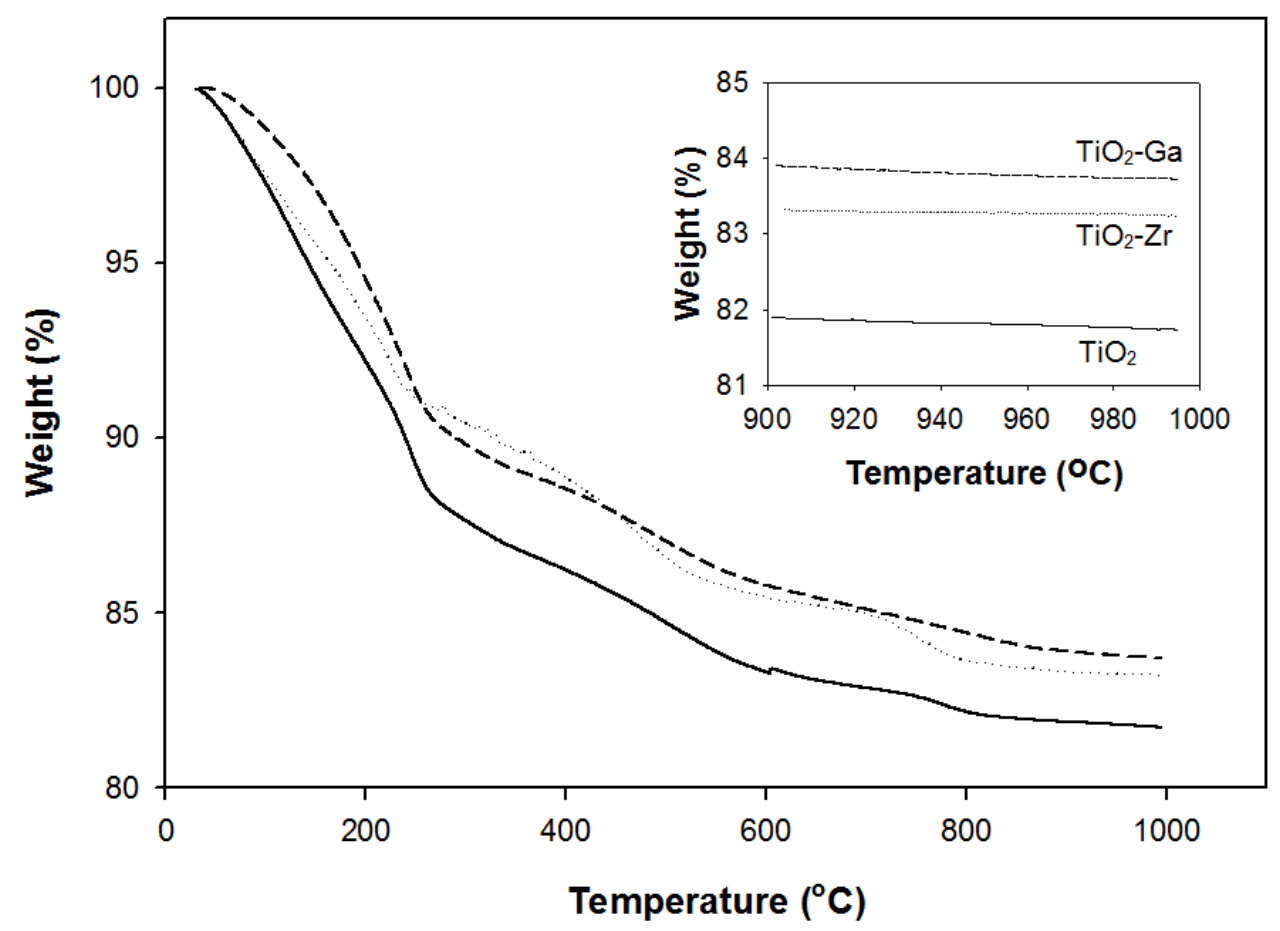

Fig. 4. TGA profile of $[\mathrm{Al}]_{\mathrm{MMAO}}$ on nano- $\mathrm{TiO}_{2}$ fillers with different modifications.

The alteration in interaction of the fillers would be resulted from many factors, but mainly involving the change in surface chemistry of the fillers by modifiers. Thus, the technique with remarkable ability to detect the surface of the fillers should be used here to clarify the matter. XPS is one of the most powerful techniques used for many applications in surface analysis. So it is interesting in using XPS to investigate the influence of modifiers on the surface chemistry and consequently, on the interaction of the fillers. The parameters obtained from XPS including binding energy (B.E.) and mass concentration of detected elements in the fillers are shown in Table 1.

Table 1. The binding energy and elemental concentration on the surface of the fillers measured by XPS.

\begin{tabular}{lcccccccccc}
\hline \multirow{2}{*}{ Filler } & \multicolumn{4}{c}{ B.E. $(\mathbf{e V}$} & \multicolumn{5}{c}{ Mass concentration (wt\%) } \\
\cline { 2 - 10 } & Ti2p & O1s & Al2p & Zr3d & Ga2p & Ti2p & O1s & Al2p & Zr3d & Ga2p \\
\hline TiO $_{2}$ & 459.4 & 532.5 & 75.0 & - & - & 0.92 & 67.99 & 31.08 & - & - \\
$\mathbf{T i O}_{2}-\mathbf{Z r}$ & 459.3 & 532.3 & 74.9 & 182.6 & - & 3.60 & 62.36 & 33.81 & 0.24 & - \\
$\mathbf{T i O}_{2}-\mathbf{G a}$ & 459.2 & 532.3 & 74.9 & - & 1118.8 & 3.85 & 62.08 & 33.54 & - & 0.53 \\
\hline
\end{tabular}

The binding energies of $\mathrm{O} 1 \mathrm{~s}$ and $\mathrm{Al} 2 \mathrm{p}$ of the entire samples exhibited nearly the same values, all of which corresponded to the binding energies of methyl aluminoxane compound (MAO or MMAO) immobilized on the fillers as reported by Hagimoto [10]. Such results suggested that there is no significant change in the state of MMAO occurred upon the modifications. However, the changes of the amount of MMAO on the fillers surface (the penetration depth for XPS is ca. $5 \mathrm{~nm}$ ) were still observed. It should be noted that for $\mathrm{O} 1 \mathrm{~s}$ atom it can also come from the $\mathrm{TiO}_{2}$. Therefore, only Al2p should be concerned in comparing the amount of MMAO on the fillers. It can be observed that the amount of Al2p (MMAO) in 
both of the modified $\mathrm{TiO}_{2}$ were higher than that of the unmodified one suggesting that both $\mathrm{Ga}$ and $\mathrm{Zr}$ assisted $\mathrm{TiO}_{2}$ in holding more MMAO onto the surface. This result is consistent with the TGA results, which found that the modified fillers have the stronger interaction with MMAO than that of the unmodified filler, hence causing the modified fillers in holding more MMAO onto the surface as observed. When comparing the amount of two modifiers: $\mathrm{Zr}$ and $\mathrm{Ga}$, it can be observed that the amount of Ga was present more than $\mathrm{Zr}$ at the surface although they were loaded at the same amount $(1 \mathrm{wt} \%)$. This implies that $\mathrm{Zr}$ was located deeper into the fillers. The different location of both elements resulted in different interaction of them.

The XPS can also prove the surface heterogeneity by using FWHM values (full width at half maximum intensity), which the higher values indicate the more heterogeneous nature to the filler surface [12]. Hence, the FWHM values of Ti2p (the main element of the fillers) were investigated to prove the surface heterogeneity for the fillers. It was found that the FWHM were in order of: $\mathrm{TiO}_{2}-\mathrm{Ga}(1.01 \mathrm{eV})>\mathrm{TiO}_{2}-\mathrm{Zr}$ $(0.97 \mathrm{eV})>\mathrm{TiO}_{2}(0.70)$. This result indicates that both modified fillers have more surface heterogeneity than the unmodified one. The poor distribution of MMAO on the filler surface may be the cause of the surface heterogeneity.

To investigate the catalytic performance of the finished fillers, they were introduced as a supported catalyst into the polymerization system to produce $\mathrm{LLDPE} / \mathrm{TiO}_{2}$ nanocomposites. The yield of the product and the polymerization time for each system were kept, and then the catalytic activities were obtained as shown in Table 2. It was found that the unmodified $\mathrm{TiO}_{2}$ exhibited the highest activities among all fillers. In fact, some authors have reported previously that $\mathrm{Ga}$ and $\mathrm{Zr}$ as modifier to fillers could increase the catalytic activity of the polymerization systems $[9,10,12]$. The lower catalytic activity for the Ga and Zr modified fillers in this place may derive from the stronger interaction with the MMAO as observed by TGA. In addition, the poor distribution of MMAO on the filler surface as noticed in the XPS results may be another reason for the catalytic performance deterioration.

Table 2. Catalytic activities upon different fillers.

\begin{tabular}{lccc}
\hline Filler & $\begin{array}{c}\text { Polymerization time a } \\
(\mathbf{s e c})\end{array}$ & $\begin{array}{c}\text { Yield } \\
(\mathbf{g})\end{array}$ & $\begin{array}{c}\text { Catalytic activity }^{\mathbf{b}} \\
\left(\times 10^{4} \mathbf{k g} \text { polymer } / \mathbf{m o l ~ Z r . h}\right)\end{array}$ \\
\hline $\mathbf{T i O}_{2}$ & 110 & 1.58 & 3.46 \\
$\mathbf{T i O}_{2}-\mathbf{Z r}$ & 123 & 1.72 & 3.35 \\
$\mathbf{T i O}_{2}-\mathbf{G a}$ & 128 & 1.48 & 2.77 \\
\hline
\end{tabular}

a A period of time used for the total 0.018 mol of ethylene to be consumed.

$\mathrm{b}$ Measurement at polymerization temperature of $70^{\circ} \mathrm{C}, \quad[$ ethylene $]=0.018 \mathrm{~mol}, \quad[\mathrm{Al}]_{\mathrm{MMAO}} /[\mathrm{Zr}]=1135, \quad[\mathrm{Al}]_{\mathrm{TMA}}$ $/[\mathrm{Zr}]_{\text {cat }}=2500$, in toluene with total volume $=30 \mathrm{~mL}$, and $[\mathrm{Zr}]_{\text {cat }}=5 \times 10^{-5} \mathrm{M}$.

\subsection{Characteristics of Polymer Nanocomposites}

The LLDPE/ $/ \mathrm{TiO}_{2}$ nanocomposites were further characterized by differential scanning calorimeter (DSC) and ${ }^{13}$ carbon nuclear magnetic resonance $\left({ }^{13} \mathrm{C}\right.$ NMR) techniques to investigate how the different fillers affect the properties of the polymers. It was found that no melting temperatures $\left(T_{m}\right)$ evaluated by DSC can be observed in all the samples (not shown) indicating non-crystalline polymers produced in this specified polymerization system. Losing crystallinity in LLDPE polymer is generally caused by an excessive level of comonomer content [13]. The amount of 1 -hexene in the polymer composites, investigated by ${ }^{13} \mathrm{C}$ NMR is shown in Table 3, also supported that result with the quite high values of 1-hexene insertion above $35 \%$. When comparing the amounts of 1-hexene among the entire samples, it was found that Zr-modified filler allowed the higher 1-hexene incorporation than the unmodified filler while Ga-modified filler allowed the lower one. This result is radically different from our previous studies [14-15] which found that both $\mathrm{Zr}$ and Ga enhanced comonomer incorporation in the polymer composite products due to serving as an anchoring unit. The lower 1-hexene incorporation in the Ga-modified filler is probably because of its heterogeneity obstructing 1-hexene access. 
Table 3. Characteristics of different $\mathrm{LLDPE} / \mathrm{TiO}_{2}$ nanocomposites.

\begin{tabular}{|c|c|c|c|c|}
\hline \multirow{2}{*}{ Sample } & \multirow{2}{*}{$\begin{array}{c}\text { 1-Hexene } \\
\text { insertion }(\mathrm{mol} \%)^{a}\end{array}$} & \multicolumn{3}{|c|}{ GPC analysis } \\
\hline & & $M_{w}\left(g \mathrm{~mol}^{-1}\right)$ & $M_{n}\left(g \mathrm{~mol}^{-1}\right)$ & MWD \\
\hline $\mathrm{TiO}_{2}$ & 40.9 & 28322 & 5871 & 4.8 \\
\hline $\mathrm{TiO}_{2-\mathrm{Ga}}$ & 36.4 & 33008 & 5543 & 6.0 \\
\hline $\mathrm{TiO}_{2}-\mathrm{Zr}$ & 44.5 & 22454 & 5547 & 4.0 \\
\hline
\end{tabular}

${ }^{\mathrm{a}}$ Obtained from ${ }^{13} \mathrm{C}$ NMR.

The molecular weight $\left(\mathrm{M}_{\mathrm{w}}\right)$, molecular number $\left(\mathrm{M}_{\mathrm{n}}\right)$, and molecular weight distribution (MWD) are also shown in Table 3. It was found that the molecular weight increased in the opposite direction of the 1hexene incorporation. This is because the presence of 1 -hexene increases the gap between the cationic active species and counter anion more separately in propagation step [16], consequently allowing the higher frequency of chain transfer reactions, leading to a decrease in polymer molecular weight [17-18] . Observing from the characteristic of $\mathrm{M}_{\mathrm{w}}$ peaks (Fig.5), it was found that $\mathrm{TiO}_{2}-\mathrm{Ga}$ provided a bimodal $\mathrm{M}_{\mathrm{w}}$ to the polymer composite products with the nearby two $M_{w}$ peaks $\left(\log M_{w} \sim 3.7\right.$ and 4.6), whereas for the remained fillers the unimodal $\mathrm{M}_{\mathrm{w}}$ characteristics were observed with the peaks at $\log \mathrm{M}_{\mathrm{w}} \sim 3.7$, which is not quite separated from the main peak. In addition, $\mathrm{TiO}_{2}-\mathrm{Ga}$ provided the broadest $\mathrm{M}_{\mathrm{w}}$ peaks as also observed from the MWD values in Table 3. The bimodal $\mathrm{M}_{\mathrm{w}}$ and broad peak were probably due to the surface heterogeneity of the fillers, which is corresponding to the XPS results. Therefore, the result of GPC was consistent with the XPS investigation above where $\mathrm{TiO}_{2}-\mathrm{Ga}$ possessed the most surface heterogeneity than the other fillers, and then it was the only filler in this study that offered the bimodal $\mathrm{M}_{\mathrm{w}}$ polymer composites.

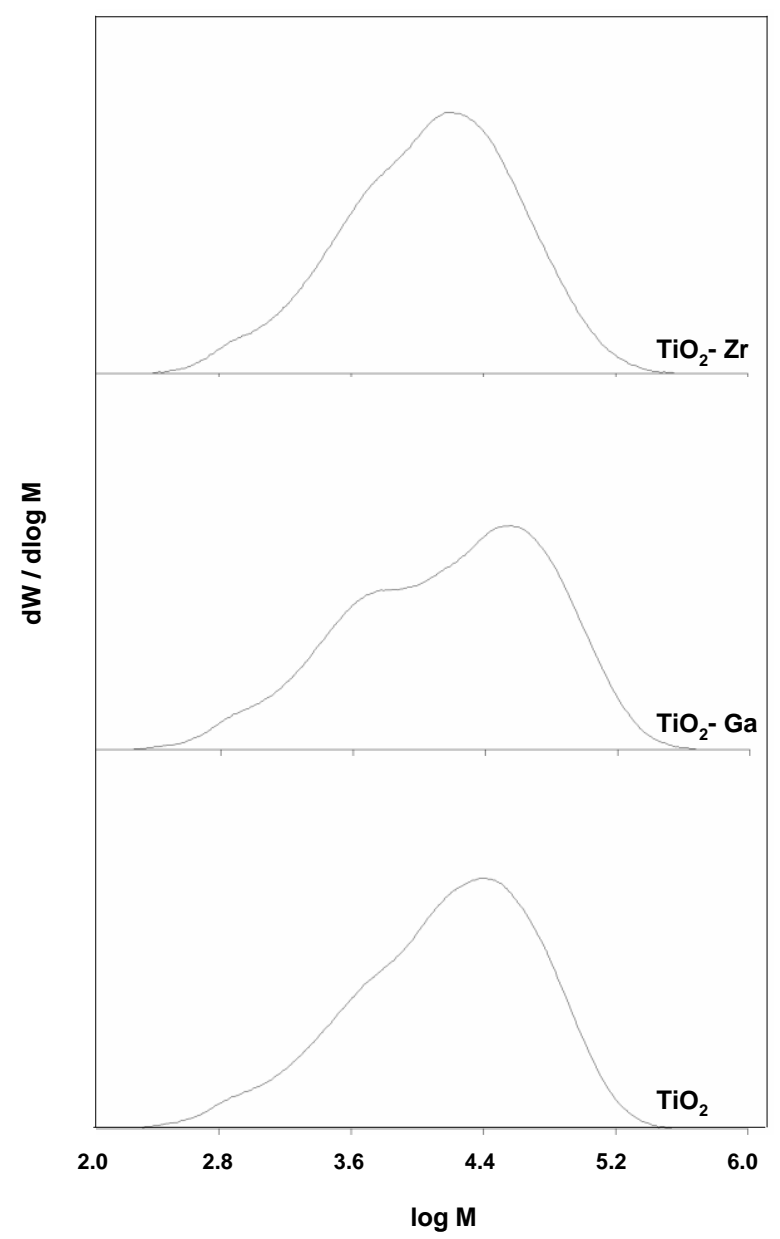

Fig. 5. GPC profiles of LLDPE obtained from different fillers. 


\section{Conclusion}

By observing the properties of three different fillers (nano- $-\mathrm{TiO}_{2}$, nano- $\mathrm{TiO}_{2}-\mathrm{Ga}$ and nano- $-\mathrm{TiO}_{2}-\mathrm{Zr}$ ), it was found that most of them including bulk phase crystallinity, surface properties and particle size were fairy similar. The major different property among them was the interaction between MMAO and the surface. It revealed that the strongest one belongs to the nano- $\mathrm{TiO}_{2}-\mathrm{Ga}$, and it led to the lowest catalytic activity for its polymerization system. However, the nano- $\mathrm{TiO}_{2}-\mathrm{Ga}$ can provide the bimodal MWD property for the nanocomposite product, due to its surface heterogeneity.

\section{Acknowledgement}

The authors gratefully acknowledge the Thailand Research Fund (TRF) and the project for Higher Education Promotion and National Research University Development (AM1088A), Office of the Higher Commission (CHE) for the financial support of this project.

\section{References}

[1] R. Nawang, I. D. Danjaji, U. S. Ishiaku, and H. Ismail, "Mechanical properties of sago starch-filled linear low density polyethylene (LLDPE) composites," Polym. Test., vol. 20, no. 2, pp. 167-172, 2001.

[2] C. J. R. Verbeek, "Highly filled polyethylene/phlogopite composites," Mater. Lett., vol. 52, no. 6, pp. 453-457, 2002.

[3] Y. Q. Huang, Y. Q. Zhang, and Y. Q. Hua, "Studies on dynamic mechanical and rheological properties of LLDPE/nano-SiO 2 composites," J. Mater. Sci. Lett., vol. 22, no. 14, pp. 997-998, 2003.

[4] G. B. Rossi, G. Beaucage, T. D. Dang, and R. A. Vaia, "Bottom-up synthesis of polymer nanocomposites and molecular composites: Ionic exchange with PMMA latex," Nano Lett., vol. 2, no. 4, pp. 319-323, 2002.

[5] Q. Wang, L. Li, and Z. Fan, "Polyethylene with bimodal molecular weight distribution synthesized by 2,6-bis(imino)pyridyl complexes of Fe(II) activated with various activators," Eur. Polym. J., vol. 40, no. 8, pp. 1881-1886, 2004.

[6] Y. Kim, Y. Han, M. H. Lee, S. W. Yoon, K. H. Choi, B. G. Song, and Y. Do, "New Half-metallocene catalysts generating polyethylene with bimodal molecular weight distribution and syndiotactic polystyrene," Macromol. Rapid Commun., vol. 22, no. 8, pp. 573-578, 2001.

[7] J. B. P. Soares and J. D. Kim, "Copolymerization of ethylene and $\alpha$-olefins with combined metallocene catalysts. I. A formal criterion for molecular weight bimodality," J. Polym. Sci., Part A: Polym. Chem., vol. 38, no. 9, pp. 1408-1416, 2000.

[8] B. Jongsomjit, S. Ngamposri, and P. Praserthdam, "Observation of bimodal polyethylene derived from $\mathrm{TiO}_{2}$-supported zirconocene/MAO catalyst during polymerization of ethylene and ethylene/1hexene," Catal. Lett. , vol. 117, no. 3-4, pp. 177-181, 2007.

[9] W. Owpradit and B. Jongsomiit, "A comparative study on synthesis of $\mathrm{LLDPE} / \mathrm{TiO}_{2}$ nanocomposites using different $\mathrm{TiO}_{2}$ by in situ polymerization with zirconocene/dMMAO catalyst," Mater. Chem. Phys. vol. 112, no. 3, pp. 954-961, 2008.

[10] H. Hagimoto, T. Shiono, and T. Ikeda, "Supporting effects of methylaluminoxane on the living polymerization of propylene with a chelating (diamide)dimethyltitanium complex," Macromol. Chem. Phy., vol. 205, no. 1, pp. 19-26, 2004.

[11] J. R. Severn, J. C. Chadwick, R. Duchateau, and N. Friederichs, “'Bound but not gagged' Immobilizing single-site a-olefin polymerization catalysts," Chem. Rev., vol. 105, no. 11, pp. 4073-4147, 2005.

[12] D. Bianchini, J. H. Z. dos Santos, T. Uozumi, and T. Sano, "Characterization of MAO-modified silicas," J. Mol. Catal. A: Chem., vol. 185, no. 1-2, pp. 223-235, 2002.

[13] H.F . Mark, "Ethylene Polymers, LLDPE." in Encyclopedia of Polymer Science and Technology, vol. 2. New York: John Wiley \& Sons, 2002, pp. 441-482.

[14] M. Wannaborworn and B. Jongsomjit, "Ethylene/1-octene copolymerization over Ga-modified $\mathrm{SiO}_{2-}$ supported zirconocene/MMAO catalyst using in situ and ex situ impregnation methods," Iran. Polym. J., vol. 18, no. 12, pp. 969-979, 2009. 
[15] T. Pothirat, B. Jongsomjit, and P. Praserthdam, "Effect of Zr-modified $\mathrm{SiO}_{2}$-supported metallocene/MAO catalyst on copolymerization of ethylene/1-octene," Catal. Lett., vol. 121, no. 3-4, pp. 266-273, 2008.

[16] F. Forlini, Z. Q. Fan, I. Tritto, P. Locatelli, and M. C. Sacchi, "Metallocene-catalyzed propene/1hexene copolymerization: Influence of amount and bulkiness of cocatalyst and of solvent polarity," Macromol. Chem. Phys., vol. 198, no. 8, pp. 2397-2408, 1997.

[17] M. de Fátima, V. Marques, O. da Silva, A. Coutinho, and A. de Araujo, "Ethylene polymerization catalyzed by metallocene supported on mesoporous materials," Polym. Bull., vol. 61, no. 4, pp. 415-423, 2008.

[18] H. Hong, Z. Zhang, T. C. M. Chung, and R. W. Lee, "Synthesis of new 1-decene-based LLDPE resins and comparison with the corresponding 1-octene- and 1-hexene-based LLDPE resins," J. Polym. Sci., Part A: Polym. Chem. , vol. 45, no. 4, pp. 639-649, 2007. 